\title{
Respectful maternity care during labor and childbirth and associated factors among women who gave birth at health institutions in the West Shewa zone, Oromia region, Central Ethiopia
}

\author{
Gizachew Abdissa Bulto ${ }^{1 *}$, Dereje Bayissa Demissie ${ }^{2 \dagger}$ and Abera Shibru Tulu ${ }^{3+}$
}

\begin{abstract}
Background: Skilled assistance during pregnancy and childbirth is one of the key interventions in reducing maternal morbidity and mortality. But studies have shown that many women across the globe experience disrespectful and abusive treatment during labor and childbirth in institutions, which forms an important barrier to improving skilled care utilization and improving maternal health outcomes. Although there are few studies done in Ethiopia, information on the status of respectful maternity care (RMC) among women during childbirth at health institutions in the West-Shewa zone is lacking. Therefore, the study aimed to assess RMC during Labor and Childbirth and associated factors among women who gave-birth at health-institutions in the West Shewa zone, Central Ethiopia.
\end{abstract}

Methods: Cross-sectional study was conducted at Health institutions in the West Shewa zone, Oromia region, Central Ethiopia. A systematic random sampling technique that uses women's delivery registration number was used to collect data. Data was collected through an exit-interview. Both bivariate and multivariable logistic regressions were used to identify associated factors.

Results: From a total of 567 women who fully responded, only 35.8\% received RMC. From categories of RMC, $76.5 \%$ of the woman is protected from physical harm/ill-treatment and 89.2\% received equitable care free of discrimination. But, only 39.3\% of woman's right to information, informed consent and preferences were protected. Giving birth at health center (AOR:5.44), discussion on the place of delivery (AOR:4.42), daytime delivery (AOR:5.56), longer duration of stay ( $\geq 13 \mathrm{~h}$ ) (AOR:2.10), involvement in decision-making (AOR:8.24), asking for consent before the procedure(AOR:3.45), current pregnancy unintended (AOR:5.56), the presence of $<3$ health-workers during childbirth (AOR:2.23) and satisfied on waiting-time to be seen (AOR:2.08) were found to be significantly associated with RMC.

(Continued on next page)

\footnotetext{
* Correspondence: gizachab@yahoo.com

'Department of Midwifery, College of Medicine and Health Sciences, Ambo University, Ambo, Ethiopia

Full list of author information is available at the end of the article
}

C C The Author(s). 2020 Open Access This article is licensed under a Creative Commons Attribution 4.0 International License, which permits use, sharing, adaptation, distribution and reproduction in any medium or format, as long as you give appropriate credit to the original author(s) and the source, provide a link to the Creative Commons licence, and indicate if changes were made. The images or other third party material in this article are included in the article's Creative Commons licence, unless indicated otherwise in a credit line to the material. If material is not included in the article's Creative Commons licence and your intended use is not permitted by statutory regulation or exceeds the permitted use, you will need to obtain permission directly from the copyright holder. To view a copy of this licence, visit http://creativecommons.org/licenses/by/4.0/ The Creative Commons Public Domain Dedication waiver (http://creativecommons.org/publicdomain/zero/1.0/) applies to the data made available in this article, unless otherwise stated in a credit line to the data. 
(Continued from previous page)

Conclusions: The proportion of RMC during labor and childbirth in the study area was low. Type of institution, discussion during ANC, time of delivery, duration of stay, involvement in decision-making, the number of health workers, waiting time and consent were identified factors. Therefore, giving emphasis to creating awareness of care providers on the standards and categories of RMC, improving care provider-client discussion, monitor and reinforcing accountability mechanisms for health workers to avoid mistreatments during labor and childbirth were recommended.

Keywords: Respectful Maternity Care, Labor and Childbirth, Health Institutions, West Shewa Zone

\section{Background}

Respectful maternity care (RMC) is an approach centered on an individual, based on principles of ethics and respect for human rights, and promotes practices that recognize women's preferences and women's and newborns' needs $[1,2]$. RMC is a universal human right that is due to every childbearing woman in every health system $[3,4]$. However, many women across the globe experience disrespectful, abusive or neglectful treatment during childbirth in health institutions [5]. The reported forms of Dis-Respect and Abuse (DRA) have been classified into seven categories: physical abuse, non-consented care, non-confidential care, non-dignified care, discrimination based on patient's attributes, abandonment of care and detention in facilities [6].

Evidence from various countries in Sub-Saharan Africa shows that women would prefer to deliver in a facility, but choose not to because of previous experiences of inadequate, low quality, and/or disrespectful care in facilities[7-9]. Despite this, reports of "disrespectful and abusive treatment" during labor and childbirth continue to appear in the world $[5,7,10]$. Given the abundant reports of disrespectful and abusive obstetric care, women in low and middle-income countries fear various undesirable procedures and may prefer to deliver at home with a traditional birth attendant $[4,11]$.

Different studies highlighted the connection between disrespect and abusive care during facility-based childbirth and a decision by women not to use facility-based childbirth services. The negative effect of DRA during childbirth on skilled delivery attendance constitutes an important barrier to increasing services utilization and enhancing maternal well-being $[8,12,13]$. In Tanzania women who experienced disrespect/abuse were less likely to plan to deliver again at the same facility [14]. Bowser and Hill found that a weak health care system and shortages in human resource contributes to disrespectful or abusive care. Health facility infrastructure, resources and commodities were mainly mentioned as a contributors for the lack of RMC [15].

Skilled assistance during pregnancy and childbirth is one of the most important interventions in reducing maternal morbidity and mortality. Efforts to increase the use of facility-based maternity care in low-income countries are unlikely to achieve the desired gains if there is no improvement in the quality of care provided, especially elements of respectful care [16]. The negative patient experiences at health institutions contribute to poor health outcomes and reinforce mistrust of institutional care. Additionally, women and families may delay or avoid seeking care in health facilities, even at the risk of their own health and that of their newborn $[17,18]$.

Ethiopian federal ministry of health in its Health Sector Transformation Plan (HSTP) has planned to increase the level of deliveries attended by skilled birth attendants from $15 \%$ in 2014 to $90 \%$ by 2020 . To help achieve the targets set, the Ministry has identified caring, respectful and compassionate $(\mathrm{CRC})$ health professionals as one of the four transformation agendas. Lack of respect for patients and their families is a common complaint and having CRC health professionals is a critical requirement to ensure equity and achieve high-quality health services on its HSTP $[19,20]$.

In Ethiopia, the pooled prevalence of disrespect and abusive care during childbirth and maternity care was 49.4\% [21]. More than two-thirds (78.6\%) of postpartum mothers in Addis Ababa, 67.1\% in Bahir Dar city and 21\% of women in four health centers of Amhara and Southern regions of Ethiopia reported as they experienced one or more categories of disrespect and abuse during labor and childbirth [22-24]. Another study in Bahir Dar city showed only $57 \%$ of mothers received RMC [25].

As indicated, disrespect and abuse during labor and childbirth is an important concern, especially in countries like Ethiopia, where the maternal mortality rate is high (412/100,000 live births) and yet the skilled birth attendance has been very low (28\%) [26].

In Ethiopia, even if there are few studies conducted on the status of disrespect and abusive treatments, data on the status of respectful maternity care and associated factors among women who give birth at health institutions in the west Shewa zone is lacking. Therefore, this study aimed to assess RMC during Labor and Childbirth and associated factors among "women who gave-birth" at health-institutions in West Shewa zone, Central, Ethiopia. Findings from this study may also help policymakers, program managers and organizations working on this area as baseline data for effective implementation of CRC in the HSTP, improving DRA treatments at health institutions. 


\section{Methods}

\section{Study design, period and area}

An institution-based cross-sectional study design was used to assess the status of RMC during Labor and Childbirth and associated factors among women who gave birth in public Health institutions of West Shewa zone, Central Ethiopia, from April 01 to June 30, 2018. Ambo town which is the capital of the zone is located $114 \mathrm{~km}$ to the west of Addis Ababa, the capital of the country. Available information from the zonal health office shows that the total population of the zone is estimated to be 2,381,079 of which 1, 214,350 is female. Currently, the health system of the zone consists of one university referral hospital, one general Hospital, five primary hospitals, ninety-two health centers and four hundred forty-seven health posts with $98 \%$ of potential health service coverage. All health centers and hospitals provide $24 \mathrm{~h}$ of labor and delivery services [27].

\section{Source population and study population}

The source population was all women who delivered at health institutions in the West Shewa zone. The study population was all women who delivered at the selected Health institutions during the data collection period and selected by a systematic random sampling. Women who were referred from other health institutions after giving birth to those selected health institutions were excluded.

\section{Sample size and Sampling procedure}

The sample size was determined by using single population proportion formula with the assumption that $78 \%$ proportion $(\mathrm{P})$ of women experienced one or more categories of disrespect and abuse from a study done at health facilities in Addis Ababa [22], at 5\% level of significance and a margin of error of $5 \%$. By considering a $10 \%$ non-response rate and design effects of 2 , the final sample size was 582 .

A simple random sampling technique was utilized to select 3 hospitals and 19 health centers that have more delivery. The total sample sizes were allocated proportionally to each of the selected hospitals and health centers by reviewing the number of deliveries attended to by each health facility. A systematic random sampling technique was used to collect data using women's delivery registration number from the delivery logbook. Data were collected from every 3rd woman who gave birth during the study period at each selected health institutions.

\section{Operational definitions}

In this study, women were considered to have received respectful maternity care during labor and childbirth if they answered yes to all of those questions assessing RMC or verification criteria used for assessing the seven categories (performance standards) of RMC during labor and childbirth [22, 25, 28].

Women were considered as experienced disrespect and abuse if they answered no to one or more of those questions assessing RMC or verification criteria used for assessing the seven categories of RMC [10, 12, 23].

\section{Data collection tools and procedures}

The questionnaires for data collection were initially prepared in English, and translated into the local language (Afan Oromo) and back into English to check for consistency with language experts. Data was collected through an exit interview by using a pre-tested structured Afan Oromo version questionnaire. We used a validated tool for assessing RMC which was adapted from the Maternal and Child Health Integrated Program. The other included questions in the questionnaire were prepared by reviewing different other related works of literature and variables identified to be measured [25, 28, 29].

Twenty-four [24] data collectors who were not working in the study area were recruited for the data collection and three [3] Master Degree holders conducted supervision during the data collection period. The training was given for data collectors and supervisors by investigators for two days. Pre-test of the questionnaire was done on $5 \%$ of the women who delivered at Holeta health center and Inchini hospital, to identify any ambiguity, check for consistency of the questionnaire, acceptability and necessary correction were made one week before the actual data collection. The filled questionnaires were collected and checked for consistencies and completeness daily by supervisors and principal investigators.

\section{Data processing and analysis}

The returned questionnaires were checked for completeness, cleaned manually, coded and entered into EPI Data version 3.1software and then exported to SPSS windows version 23 for further analysis. Bivariate analysis was used primarily to check which variables have an association with the dependent variable individually. Variables which were found to have an association with the dependent variable $(p$-value $\leq 0.2)$ were then entered into Multiple Logistic regression for controlling the possible effect of confounders and finally the variables which have significant association were identified based on AOR, with $95 \% \mathrm{CI}$ and $p$-value $\leq 0.05$ to fit into the final regression model.

\section{Ethical considerations}

Ethical clearance was obtained from the research review and ethics committee of Ambo University, collage of Medicine and Health Sciences. 


\section{Results}

A total of 567 women fully responded to the interview questionnaire making a response rate of $97.4 \%$. The majority of respondents, 263 (46.4\%) had their childbirth in health centers, 546 (96.3\%) were married, 303 (53.4\%) were protestant religion followers, and 530 (93.5\%) belongs to the Oromo ethnic group. Regarding women's occupational status 202 (35.6\%), were housewives and about 395 (69.7\%) were urban residents. One-fourth of the respondents attended primary education 150 (26.5\%). The mean age of respondents was 26.9 years with a standard deviation of 5.2 years (Table 1 ).

\section{Obstetric Related Characteristics of Women}

The result of this study indicated that the majority of respondents 417 (73.5\%) were multiparous and 537 (94.7\%) had ANC follow up. Of the total respondents, $453(79.9 \%)$ of them gave birth with spontaneous vaginal delivery, 549 (96.8\%) were live birth, and in only 54 $(9.5 \%)$ of them, there were cultural practices (coffee or porridge) after delivery (Table 2 ).

\section{Prevalence and Categories of Respectful Maternity Care}

The overall proportion of women who received RMC during labor and childbirth was 203 (35.8\%) [95\% CI: 31.739.7], but a significant number of women 364 (64.2\%) had experienced disrespect and abusive care during childbirth [95\% CI: 60.3-68.3]. Only $47.3 \%$ of women who gave birth at health centers and $25.8 \%$ who gave birth at hospitals received RMC (, $P=0.000)$.

From categories of RMC, 434 (76.5\%) of the women were protected from physical harm or ill-treatment and 506 (89.2\%) received equitable care free of discrimination. More than half 319 (56.3\%) of respondents were never left without care or unattended. But, only 223 (39.3\%) of a woman's right to information, informed consent, and preferences were protected (Fig. 1).

From the categories of being free from physical harm or ill-treatment, 498 (87.8\%) of mothers were never physically forced or abrasively handled by care providers and $416(73.4 \%)$ of them were provided comfort or pain relief as necessary.

Woman's right to information, informed consent and choice or preferences is the least respected from categories of RMC. In about 419 (73.9\%) of women, they were allowed to move during labor and 312(55.0\%) were allowed to assume a position of choice during birth. For about $369(65.1 \%)$ of women care providers responded to their questions with promptness, politeness and truthfulness and 356 (62.8\%) of them explained what is being done and to expect throughout childbirth.
Regarding the confidentiality and privacy of the respondents, the providers kept a patient's file in limited access areas for 531 (93.7\%) of them and used drapes or covering to protect their privacy in 487 (85.9\%). Four hundred and forty-two (78.0\%) of women were not insulted, intimidated, threatened, shouted at, scolded, laughed, scorned or coerced. In about 519 (91.5\%) of respondents, the provider did not show disrespect to the women based on some attributes. The women were never left without care or unattended in $353(62.3 \%)$ of them and $563(99.3 \%)$ were not forced to stay against their will (Table 3).

\section{Factors associated with Respectful Maternity care during Childbirth}

The result of the bivariate analysis showed that; respondent's educational status, religion, residence, and sex of provider are socio-demographic factors that are found to be significant with RMC at a p-value of 0.2 or less. Level of health institutions, requesting for consent, duration of stay, visit type of current delivery, number of institutional delivery, waiting time, current pregnancy status, number of attending personnel, discussion about place of delivery, availability of cultural practices, time of delivery and involvement in decision-making were other factors identified at $p$-value 0.2 or less.

On multivariable logistic regression; the type of health institutions, taking consent before procedure, current pregnancy status, number of health workers during childbirth, discussion on the place of delivery with health worker during ANC, time (shift) of delivery, duration of stay at health institutions, involvement in decisionmaking and waiting time to be seen by health workers were found to be significantly associated with respectful maternity care at $P$-value of $\leq 0.05$.

This study identified that those women who gave birth at health centers were 5 times (AOR $=5.44,95 \% \mathrm{CI}: 2.93$, 10.08) more likely to receive respectful care as compared to those who gave birth at a general hospital. Women who stayed 13 to $24 \mathrm{~h}$ and more than $24 \mathrm{~h}$ at health facility were 2.1 and almost 2 times more likely to receive respectful maternity care than those who stayed $12 \mathrm{~h}$ or less $(\mathrm{AOR}=2.10,95 \% \mathrm{CI}: 1.24,3.56)$ and $(\mathrm{AOR}=1.94$, 95\%CI: $1.08,3.46)$ respectively.

This study revealed that women whose current pregnancy was unwanted were 5.56 times more likely to get $\mathrm{RMC}$ than those of a wanted pregnancy $(\mathrm{AOR}=5.56$, 95\%CI: 2.56-12.11). Women who had discussed on the place of delivery with health workers during ANC visits were 4.42 times more likely to receive RMC during labor and Childbirth than those who did not $(\mathrm{AOR}=4.42$, 95\%CI: 2.15-9.11). 
Table 1 A Socio-Demographic characteristic of mother's who gave birth at public health facilities in the west Shewa zone, Oromia region, central Ethiopia, 2018

\begin{tabular}{|c|c|c|c|}
\hline Characteristics & Categories & Number $(N=567)$ & Percent (\%) \\
\hline \multirow[t]{3}{*}{ Type of Institution } & Health center & 263 & 46.4 \\
\hline & Primary Hospital & 157 & 27.7 \\
\hline & General Hospital & 147 & 25.9 \\
\hline \multirow[t]{3}{*}{ Age in years } & $17-24$ & 192 & 33.9 \\
\hline & $25-29$ & 205 & 36.2 \\
\hline & More than 29 & 170 & 30.0 \\
\hline \multirow[t]{2}{*}{ Marital Status } & Married & 546 & 96.3 \\
\hline & Other marital Status ${ }^{a}$ & 21 & 3.7 \\
\hline \multirow[t]{4}{*}{ Religion } & Orthodox & 225 & 39.7 \\
\hline & Protestant & 303 & 53.4 \\
\hline & Muslim & 31 & 5.5 \\
\hline & Other Religion ${ }^{\mathrm{b}}$ & 8 & 1.4 \\
\hline \multirow[t]{3}{*}{ Ethnicity } & Oromo & 530 & 93.5 \\
\hline & Amhara & 30 & 5.3 \\
\hline & Other Ethnicity ${ }^{c}$ & 7 & 1.3 \\
\hline \multirow[t]{5}{*}{ Educational Status } & Unable to read \& write & 86 & 15.2 \\
\hline & Able to read and write & 60 & 10.6 \\
\hline & Primary education & 150 & 26.5 \\
\hline & Secondary Education & 133 & 23.5 \\
\hline & Collage and above & 138 & 24.3 \\
\hline \multirow[t]{6}{*}{ Mothers Occupation } & Government Employee & 123 & 21.7 \\
\hline & Housewife & 202 & 35.6 \\
\hline & Farmers & 85 & 15.0 \\
\hline & Merchant & 78 & 13.8 \\
\hline & Private Employee' & 66 & 11.6 \\
\hline & Other Occupation $^{d}$ & 13 & 2.3 \\
\hline \multirow[t]{2}{*}{ Mothers Residence } & Urban & 395 & 69.7 \\
\hline & Rural & 172 & 30.3 \\
\hline \multirow[t]{3}{*}{ Average Monthly Income } & Less than 2000 & 294 & 51.9 \\
\hline & More than 2000 & 273 & 48.1 \\
\hline & \multicolumn{3}{|c|}{ Mean $=2787.1$ with SD of 2450.85 Ethiopian Birr, Median $=2000.00$} \\
\hline
\end{tabular}

Keys: ${ }^{a}$ Divorced, widowed \& single, ${ }^{\mathrm{b}}$ Wakefata \& Catholic, ${ }^{\mathrm{c}}$ Gurage \& Tigre, ${ }^{\mathrm{d}}$ Student \& Daily laborers

In the current study the number of attending health care providers was found to affect RMC; in which those who were attended to by 2 or fewer providers were 2.23 times more likely to receive RMC than those who were attended by 3 or more (AOR $=2.23,95 \%$ CI: 1.30,3.82).

Taking consent before doing a procedure was found to affect RMC, which indicated that women who gave their consent before the procedure were 3.45 times more likely to get respectful care than those who did not consent $(\mathrm{AOR}=3.45,95 \% \mathrm{CI}: 1.56-7.61)$. Women who gave birth during the day time were 5.56 times more likely to receive respectful care than nighttime shift $(\mathrm{AOR}=5.56$, 95\%CI: 3.47-8.91).
Those women who got involved in decision-making about their care were found to be 8.24 times more likely to receive respectful care than those who weren't involved $(\mathrm{AOR}=8.24,95 \% \mathrm{CI}: 3.63-18.67)$. Women who were satisfied with their current waiting time to be seen by health workers were 2 times more likely to get RMC than those who weren't (AOR $=2.08$, 95\%CI: 1.02-4.25) (Table 4).

\section{Discussion}

The current study indicated that overall, only one-third of women received RMC during labor and childbirth at public health institutions in the West Shewa Zone 
Table 2 Obstetric characteristics of mother's who gave birth at public health facilities in the west Shewa zone, Oromia region, central Ethiopia, 2018. $(N=567)$

\begin{tabular}{|c|c|c|c|}
\hline Characteristics & Categories & Number & Percent (\%) \\
\hline \multirow[t]{3}{*}{ Number of Parity } & Primi-para & 150 & 26.5 \\
\hline & $2-3$ & 211 & 37.2 \\
\hline & $\geq 4$ & 206 & 36.3 \\
\hline \multirow[t]{2}{*}{ Current pregnancy Intended/wanted } & Yes & 507 & 89.4 \\
\hline & No & 60 & 10.6 \\
\hline \multirow[t]{4}{*}{ Number of ANC follow ups } & No ANC follow up & 30 & 5.3 \\
\hline & Once to twice & 90 & 15.9 \\
\hline & Three times & 176 & 31.0 \\
\hline & Four and above & 271 & 47.8 \\
\hline \multirow[t]{3}{*}{ Providers discussed about place of delivery during ANC } & Yes & 462 & 81.5 \\
\hline & No & 75 & 13.2 \\
\hline & No ANC follow up & 30 & 5.3 \\
\hline \multirow[t]{2}{*}{ Discussed place of delivery with partner } & Yes & 409 & 72.1 \\
\hline & No & 158 & 27.9 \\
\hline \multirow[t]{3}{*}{ Visit type for current delivery } & New or My first time & 225 & 39.7 \\
\hline & Repeat Visits & 298 & 52.6 \\
\hline & Referred from other institution & 44 & 7.8 \\
\hline \multirow[t]{2}{*}{ Labor started } & Spontaneous & 526 & 92.8 \\
\hline & Induced & 41 & 7.2 \\
\hline \multirow[t]{2}{*}{ Duration spent on labor } & Less than $12 \mathrm{~h}$ & 416 & 73.4 \\
\hline & More than $12 \mathrm{~h}$ & 151 & 26.6 \\
\hline \multirow[t]{3}{*}{ Total current stay at Health facilities } & $12 \mathrm{~h}$ or less & 277 & 48.9 \\
\hline & 13 to $24 \mathrm{~h}$ & 147 & 25.9 \\
\hline & $25 \mathrm{~h}$ and above & 143 & 25.2 \\
\hline \multirow[t]{3}{*}{ Mode of Delivery } & Spontaneous vaginal delivery & 453 & 79.9 \\
\hline & Assisted vaginal Delivery & 45 & 7.9 \\
\hline & Cesarean section & 69 & 12.2 \\
\hline \multirow[t]{2}{*}{ Outcomes of delivery } & Alive & 549 & 96.8 \\
\hline & Stillbirth & 18 & 3.2 \\
\hline \multirow[t]{2}{*}{ Condition of mother during childbirth } & No complication & 498 & 87.8 \\
\hline & Had Complications & 69 & 12.2 \\
\hline \multirow[t]{2}{*}{ Time of delivery } & Day time & 301 & 53.1 \\
\hline & Nighttime & 266 & 46.9 \\
\hline \multirow[t]{3}{*}{ Who attended your delivery } & Midwife & 420 & 74.1 \\
\hline & Nurse or Health Officer & 39 & 6.9 \\
\hline & Doctors or Emergency Surgeon & 108 & 19.0 \\
\hline \multirow[t]{2}{*}{ Sex of Provider } & Male & 287 & 50.6 \\
\hline & Female & 280 & 49.4 \\
\hline \multirow[t]{5}{*}{ Procedures Done } & Episiotomy & 142 & 25.0 \\
\hline & Fundal pressure & 65 & 11.5 \\
\hline & Manual removal of placenta & 24 & 4.2 \\
\hline & Instrumental Delivery & 39 & 6.9 \\
\hline & Cesarean Section & 69 & 12.2 \\
\hline
\end{tabular}


Table 2 Obstetric characteristics of mother's who gave birth at public health facilities in the west Shewa zone, Oromia region, central Ethiopia, 2018. ( $N=567)$ (Continued)

\begin{tabular}{|c|c|c|c|}
\hline Characteristics & Categories & Number & Percent (\%) \\
\hline \multirow[t]{3}{*}{ Asked your consent before performing procedure } & Not asked me & 79 & 13.9 \\
\hline & Yes & 240 & 42.3 \\
\hline & No Procedure done for me & 248 & 43.7 \\
\hline \multirow[t]{4}{*}{ Number of attendants during childbirth } & One & 73 & 12.9 \\
\hline & Two & 240 & 42.3 \\
\hline & Three & 111 & 19.6 \\
\hline & Four and above & 143 & 25.2 \\
\hline \multirow[t]{2}{*}{ Anyone other than concerned provider gets access to see you during LAD } & Yes & 92 & 16.2 \\
\hline & No & 475 & 83.8 \\
\hline \multirow[t]{2}{*}{ There are cultural practices for mothers after delivery (Coffee or porridge) } & Yes & 54 & 9.5 \\
\hline & No & 513 & 90.5 \\
\hline \multirow[t]{2}{*}{ Admitted to maternity waiting home before labor started } & Yes & 32 & 5.6 \\
\hline & No & 535 & 94.4 \\
\hline \multirow[t]{2}{*}{ Do you want to have a child in the future } & Yes & 433 & 76.4 \\
\hline & No & 134 & 23.6 \\
\hline
\end{tabular}

[35.8\% (95\% CI: 31.7-39.7)]. This is in line with the study done in Bahirdar town $32.9 \%$ of mothers experienced respectful and non-abusive care [25]. However, this is higher than the study done in Addis Ababa where $21.4 \%$ of respondents received respectful and nonabusive care [18]. This variation might be due to the difference in the study setting and study population in which Addis Ababa's study was only limited to the town and they excluded those mothers who had an elective or emergency cesarean section.

The current finding is lower than the study done in Bahirdar town, Ethiopia in which $57 \%$ of women experienced RMC [25]. In Northern Ethiopia, 22\% reported at least one incident of DRA [30]. In Addis Ababa 82.4\% had received RMC [31], and in another study in Addis Ababa at least one form of DRA in 36\% of the observations [28]. Health centers in two regions of Ethiopia also showed $21.1 \%$ of respondents reported DRA [32] and a systematic review in Ethiopia also indicated $49.4 \%$ of DRA [21]. The current finding (35.8\%) is also lower than the study done in urban Tanzania (15\%) of postpartum women reported at least one instance of DRA [17]. Another study done in Tanzania $19.48 \%$ reported DRA on exit from the health facilities and $28.21 \%$ on follow-up interview in the community [12]. From the study done in Kenya, $20 \%$ of women had reported any form of DRA

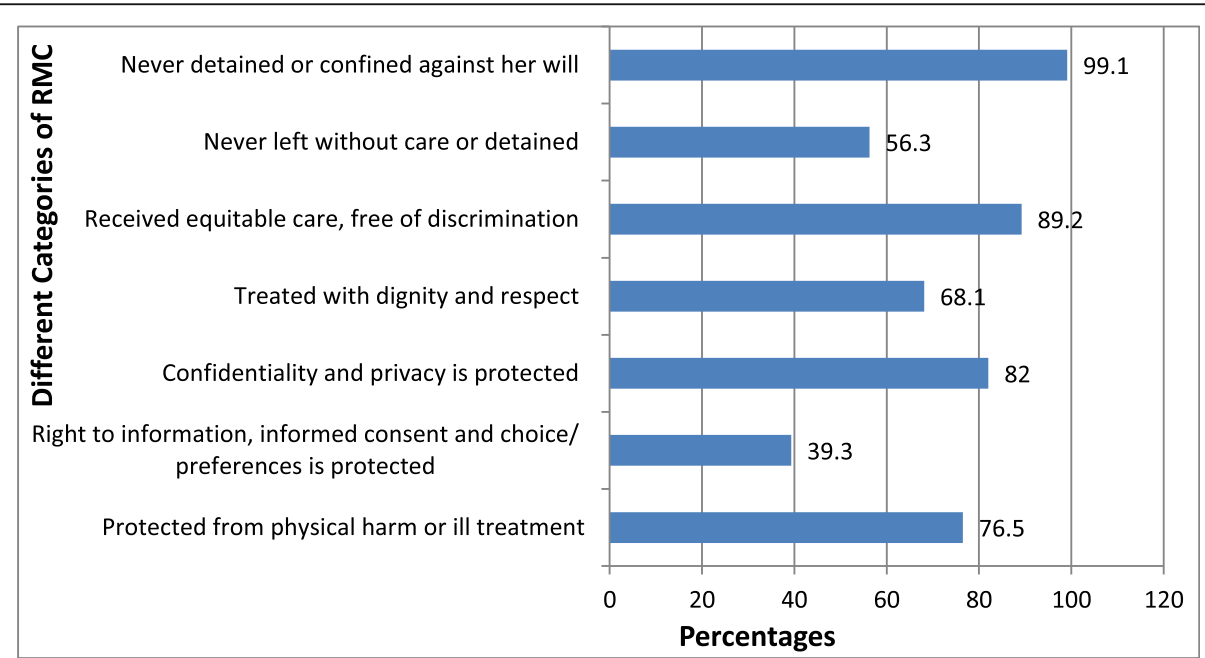

Fig. 1 Prevalence of different categories of RMC during childbirth at public health facilities in West Shewa zone, Oromia region, Ethiopia, 2018 
Table 3 Proportions of different categories of RMC during labor and Childbirth at public health facilities in West Shewa Zone, Oromia region, Ethiopia, 2018. $(N=567)$

\begin{tabular}{|c|c|c|c|c|}
\hline \multirow[t]{2}{*}{ Categories of RMC } & \multicolumn{2}{|l|}{ RMC } & \multicolumn{2}{|l|}{ DRA } \\
\hline & Number & $\overline{\text { Percent }}$ & Number & Percent \\
\hline \multicolumn{5}{|l|}{ 1. The woman is protected from physical harm or ill-treatment } \\
\hline Never used physical force/abrasive behavior with the woman & 498 & 87.8 & 69 & 12.2 \\
\hline Never physically restrains woman & 504 & 88.9 & 63 & 11.1 \\
\hline Touches/demonstrate caring in a culturally appropriate way & 530 & 93.5 & 37 & 6.5 \\
\hline Never separates woman from her baby unless & 552 & 97.4 & 15 & 2.6 \\
\hline Does not deny food or fluid to women in labor & 550 & 97.0 & 17 & 3.0 \\
\hline Provides comfort/pain-relief as necessary & 493 & 86.9 & 74 & 13.1 \\
\hline \multicolumn{5}{|l|}{ 2. The woman's right to information, informed consent and choice/ preferences is protected } \\
\hline Great and introduces self to woman and companion & 385 & 67.9 & 182 & 32.1 \\
\hline Encourages companion to remain with woman & 387 & 68.3 & 180 & 31.7 \\
\hline Encourages woman and her companion to ask questions & 337 & 59.4 & 230 & 40.6 \\
\hline Responds to questions with promptness, politeness \& truthfulness & 369 & 65.1 & 198 & 34.9 \\
\hline Explains what is being done \& to expect throughout $L A D$ & 356 & 62.8 & 211 & 37.2 \\
\hline Gives periodic updates on status and progress of labor & 389 & 68.6 & 178 & 31.4 \\
\hline Allows the woman to move about during labor & 419 & 73.9 & 148 & 26.1 \\
\hline Allows woman to assume position of choice during birth & 312 & 55.0 & 255 & 45.0 \\
\hline Obtains consent or permission prior to any procedure & 350 & 61.7 & 217 & 38.3 \\
\hline \multicolumn{5}{|l|}{ 3. Confidentiality and privacy is protected } \\
\hline Confirms patient files are stored in locked cabinets with limited access & 531 & 93.7 & 36 & 6.3 \\
\hline Uses curtains or other visual barrier to protect woman & 518 & 91.4 & 49 & 8.6 \\
\hline Uses drapes/covering appropriate to protect woman's privacy & 487 & 85.9 & 80 & 14.1 \\
\hline \multicolumn{5}{|l|}{ 4. The woman is treated with dignity and respect. } \\
\hline Speaks politely to woman and companion & 513 & 90.5 & 54 & 9.5 \\
\hline Allows woman and her companion to observe cultural practices as much as possible & 449 & 79.2 & 118 & 20.8 \\
\hline $\begin{array}{l}\text { Never makes insults, intimidation, threats, shouted at, scolded, laughed, scorned or coerces woman or her } \\
\text { companion }\end{array}$ & 442 & 78.0 & 125 & 22.0 \\
\hline \multicolumn{5}{|l|}{ 5. The woman receives equitable care, free of discrimination } \\
\hline Speaks to the woman in a language and at a language-level that she understands & 547 & 96.5 & 20 & 3.5 \\
\hline Doesn't show disrespect to women based on any specific attribute & 519 & 91.5 & 48 & 8.5 \\
\hline \multicolumn{5}{|l|}{ 6. The woman is never left without care } \\
\hline Encourages woman to call if needed & 474 & 83.6 & 93 & 16.4 \\
\hline Comes quickly when woman calls or after decision & 397 & 70.0 & 170 & 30.0 \\
\hline Never leaves woman alone or unattended & 353 & 62.3 & 214 & 37.7 \\
\hline \multicolumn{5}{|l|}{ 7. The woman is never detained or confined against her will } \\
\hline Facility doesn't have a policy to detain women who don't pay. & 564 & 99.5 & 3 & 0.5 \\
\hline Don't been forced to stay against your will & 563 & 99.3 & 4 & 0.7 \\
\hline
\end{tabular}

[33]. In another multi-level study in Kenya DRA decreased from 20 to $13 \%$ [34]. The possible reason for this variation might be due to the difference in the study setting in which the current study was conducted both in urban and rural settings unlike studies done in Bahirdar town, Addis Ababa city and Tanzania. The presence of projects working in the area in Tanzania, Kenya, northern Ethiopia, a study by Kathleen P et al. Additionally, the variations in the health care system with Tanzania and Kenya might be the possible reasons.

Although RMC is a universal right of every childbearing woman in the health care system, they may still experience disrespect and abusive care during childbirth $[3,4]$. In the current study more than four-fifths of the 
Table 4 Factors associated with Respectful Maternity care during labor and childbirth at health facilities in West Shewa Zone, Oromia region, central Ethiopia, 2018

\begin{tabular}{|c|c|c|c|c|c|}
\hline \multirow[t]{2}{*}{ Variables } & \multicolumn{2}{|c|}{ Received RMC service } & \multirow{2}{*}{$\begin{array}{l}\text { Adjusted OR } \\
95 \% \mathrm{Cl}\end{array}$} & \multirow{2}{*}{$\begin{array}{l}\text { Adjusted OR } \\
95 \% \mathrm{Cl}\end{array}$} & \multirow{2}{*}{$\begin{array}{l}\boldsymbol{P} \text { - } \\
\text { value }\end{array}$} \\
\hline & Yes & No & & & \\
\hline \multicolumn{6}{|c|}{ Type of health Facility } \\
\hline Health Center & $126(47.9)$ & 137(52.1) & $2.46(1.59,3.80)$ & $5.44(2.93,10.08)$ & $0.000^{*}$ \\
\hline Primary Hospital & $37(23.6)$ & $120(76.4)$ & $0.82(0.49,1.38)$ & $1.13(0.61,2.09)$ & 0.686 \\
\hline General Hospital & $40(27.2)$ & 107(72.8) & 1 & 1 & 0.000 \\
\hline \multicolumn{6}{|c|}{ Asked for consent before the procedure } \\
\hline Not asked me & 14(17.7) & $65(82.3)$ & 1 & 1 & $0.001^{*}$ \\
\hline Yes asked & 103(42.9) & 137(57.1) & $3.49(1.85,6.56)$ & $3.45(1.56,7.61)$ & $0.002^{*}$ \\
\hline No procedure & $86(34.7)$ & $162(65.3)$ & $2.46(1.30,4.64)$ & $1.51(0.69,3.26)$ & 0.299 \\
\hline \multicolumn{6}{|c|}{ Is current pregnancy wanted } \\
\hline Yes wanted & 173(34.1) & $334(65.9)$ & 1 & 1 & $0.000^{*}$ \\
\hline Not wanted & $30(50.0)$ & $30(50.0)$ & $1.93(1.12,3.30)$ & $5.56(2.56,12.11)$ & \\
\hline \multicolumn{6}{|c|}{ Number of health workers during childbirth } \\
\hline Two or less & 132(42.2) & 181(57.8) & $1.88(1.31,2.67)$ & $2.23(1.30,3.82)$ & \\
\hline Three or more & $71(28.0)$ & 183(72.0) & 1 & 1 & $0.003^{*}$ \\
\hline \multicolumn{6}{|c|}{ Discussed on place of delivery with health worker during ANC } \\
\hline Yes & 185(40.0) & $277(60.0)$ & $3.22(1.88,5.54)$ & $4.42(2.15,9.11)$ & \\
\hline No & 18(17.1) & $87(82.9)$ & 1 & 1 & $0.000^{*}$ \\
\hline \multicolumn{6}{|c|}{ Time (shift) of delivery } \\
\hline Day time & 148(49.2) & 153(50.8) & $3.71(2.55,5.38)$ & $5.56(3.47,8.91)$ & \\
\hline Nighttime & $55(20.7)$ & $211(79.3)$ & 1 & 1 & $0.000^{*}$ \\
\hline \multicolumn{6}{|c|}{ Duration of stay at health facilities } \\
\hline $12 \mathrm{~h}$ or less & $79(28.5)$ & 198(71.5) & 1 & 1 & $0.009^{*}$ \\
\hline 13 to $24 \mathrm{~h}$ & $68(46.3)$ & $79(53.7)$ & $2.15(1.42,3.27)$ & $2.10(1.24,3.56)$ & 0.005 \\
\hline More than $24 \mathrm{~h}$ & $56(39.2)$ & $87(60.8)$ & $1.61(1.05,2.46)$ & $1.94(1.08,3.46)$ & 0.025 \\
\hline \multicolumn{6}{|c|}{ Involvement in decision-making } \\
\hline Involved & 194(40.6) & $284(59.4)$ & $6.07(2.97,12.38)$ & $8.24(3.63,18.67)$ & \\
\hline Not involved & $9(10.1)$ & 80(89.9) & 1 & 1 & $0.000^{*}$ \\
\hline \multicolumn{6}{|c|}{ Waiting time to be seen by the health worker' } \\
\hline Yes satisfied & 188(38.0) & $307(62.0)$ & $2.32(1.28,4.22)$ & $2.08(1.02,4.25)$ & \\
\hline Not satisfied & 15(20.8) & 57(79.2) & 1 & 1 & $0.045^{*}$ \\
\hline
\end{tabular}

*variables found to be statistically significant at a $p$-value of less than 0.05

women, received equitable care and their confidentiality and privacy protected. Three fourth of women were protected from physical harm or ill-treatment. Women never left without care and the right to consented care were the least respected categories of RMC.

A study done in Bahirdar indicated that; providing a discrimination-free, friendly and abuse-free care to be the commonly practiced category of RMC [25]. Another study identified physical abuse and non-consented care were the commonly experienced categories of DRA [23]. In Addis Ababa study showed that in one-third of the women physical harm or ill-treatment were not protected, while women left without care constitute almost two-fifth. In 33\% of hospitals and $9.4 \%$ of health centers their privacy was not protected and $94.8 \%$ of women have experienced nonconsented care [18]. In another study by Kitaw M. et al., one in nine women received discrimination-free and with no abandonment of care. But, only one-fifth of women received dignified care during their childbirth [31]. The study in two regions in Ethiopia indicated non-consented care, lack of privacy, non-confidential care, were the commonly observed forms of DRA [32]. The pooled data in Ethiopia, also indicated, abandonment of care, non-confidential care and physical abuse as common forms of mistreatments [21]. These shows the proportion of each category of RMC among different studies in Ethiopia varies. 
These variations might be due to the differences in the study setting, resulting in the different prevalence of RMC categories among health institutions (Hospitals vs. Health centers), town versus rural settings and different cadres in the health care system. This is highlighting as there is a need for specific local interventions for different settings to lower the forms of DRA in Ethiopia.

From a study done in Kenya and Tanzania relatively lower proportion of all forms of DRAs were reported, indicating that a large proportion of women in Ethiopia are experiencing disrespectful and abusive care during labor and childbirth [17, 33].

This study identified that the type of health facility in the health care system was significantly associated with RMC. Women who gave birth at health centers were more likely to receive respectful care as compared to those who gave birth in the general hospital. This is in-line with the study done in Addis Ababa that indicated as there was a significant difference between the health centers and hospitals [18] and from the study done in Malawi the odds of a health provider shouting at a woman were lower in health centers compared to hospitals [35] This is may be due to the presence of more number of caseloads compared to the available number of human resources at hospitals than in health centers.

Maternal stay at the health facility was also found to be significantly associated with RMC during labor and childbirth. Mothers who stayed 13 to $24 \mathrm{~h}$ and more than $24 \mathrm{~h}$ at health institutions were almost 2 times more likely to receive $\mathrm{RMC}$ than those who stayed less than $12 \mathrm{~h}$. This finding is in agreement with a study done in Tanzania where women who stayed less than 1 day in the facility for delivery were 1.35 times more likely to report experiences of DRA [12]. The reason for this might be due to the fact that those women who stayed longer may become familiar with the health workers and are more likely to receive customary services.

Women who gave birth during the day time were 5.56 times more likely to receive respectful care than a nighttime shift. In agreement with this, a study done in Kenya identified delivering at night was associated with a higher risk of DRA and had greater odds of reporting physical abuse than those delivering during the day [34]. This might be due to the fact that during day time there are more resources/infrastructures available and the number of health workers than at nighttime in which only one health worker might be assigned for duty in health centers and also very weak supervision from senior health workers and managers during nighttime.

This study revealed that women whose current pregnancy was unwanted were 5.56 times more likely to get RMC than those of a wanted pregnancy. In agreement with this study conducted in Bahirdar also showed the odds of experiencing DRA was $76 \%$ less among those unplanned or unwanted pregnancy [25]. This is may be due to the fact that those women with an unwanted pregnancy were less likely to be worried about the outcomes and were multiparous in the current study.

The result also has shown that women who had discussed on a place of delivery with health workers during ANC were 4.42 times more likely to receive RMC than those who did not. A study done in Bahirdar indicated that respondents with fewer than 4 ANC visits were more likely to have been disrespected and abused than those with $\geq 4$ ANC visits [23]. The reason for this might be because women who had ANC and discussed on a place of delivery were more likely to be familiar with the health care providers, since majority of them in the current study gave birth at the same facility.

In the current study, the number of attending health care provider was found to be significantly associated with RMC during labor and childbirth. Mothers who were attended to by 2 or fewer providers were 2.23 times more likely to receive RMC than those who were attended by 3 or more. This is may be due to mothers do not want to show their private body to more number of providers.

Taking consent before doing a procedure was found to affect RMC. It was shown that women who gave their consent before the procedure were 3.45 times more likely to get respectful care than those who did not consent. Those women who got involved in the decisionmaking about their care were found to be 8.24 times more likely to receive respectful care than those who were not involved. The reason might be that in our study area there is a wrong perception among some health care providers that mothers might feel more pain if informed before performing procedures like episiotomy, manual removal of placentas and others. Thus, they prefer doing those procedures without informing the clients and even sometimes performs without providing analgesia. This result also highlights the need for involving mothers in all types of care they receive from health facilities.

Women who were satisfied with their waiting time to be seen by health worker were 2 times more likely to get RMC than those who were not. The reason for this might be due to women who were not satisfied were likely to feel as they were neglected or left without care if not seen by health workers after admission.

Limitation of the study: Though the problem of recall bias was minimized by conducting exit interview for postpartum mothers immediately; the current study is not free of social desirability bias in which some mothers may report the service as positive experiences while they are in the health facilities. As a strength, the study tried to cover a large number of health facilities including health centers and hospitals in the West Shewa zone providing services for over 2.3 million peoples. 


\section{Conclusions}

The proportion of RMC during labor and childbirth in health institutions in the west Shewa zone was low. Giving birth at the health center, discussion on the place of delivery with health workers during ANC, day time delivery, longer duration of stay at health facility ( $\geq 13 \mathrm{~h}$ ), involvement in decision-making, consent before the procedure, current pregnancy not wanted, presence of $<3$ health workers during childbirth, and satisfied with waiting time to be seen by a health worker were found to be significantly associated with RMC.

Therefore, health institutions and all other stakeholders should give due emphasis on creating awareness of care providers on the standards and categories of RMC, and emphatically consider those identified factors for intervention. Additionally, monitoring and reinforcing accountability mechanisms for health workers to avoid mistreatments, and supporting them to provide the service with respect and compassion during labor and childbirth. Further research involving observation is also recommended to get more information about RMC services.

\section{Abbreviations}

ANC: Ante Natal Care; AOR: Adjusted Odds Ratio; CRC: Caring, Respectful and Compassionate; DRA: Disrespect and Abuse; HSTP: Health Sector Transformation Plan; LAD: Labor And Delivery; RMC: Respectful Maternity Care

\section{Acknowledgements}

We are grateful to Ambo University, College of Medicine and Health Sciences for funding this research; west Shewa zonal Health Office and health institutions for their support during proposal development. We also want to extend our appreciation to all study participants for providing the necessary information.

\section{Authors' contributions}

GAB, conceptualized the study, designed the study instrument, secured study funds, conducted data analysis and wrote the first draft and subsequent drafts of the manuscript as principal investigator. DBD and AST take part in designing the study tool, coordinated data collection and supervision, participated in data analysis and revised subsequent drafts. All authors read and approved the final manuscript.

\section{Funding}

Funding for this study was obtained from Ambo University. The university had no role in the design of the study and collection, analysis, and interpretation of data.

\section{Availability of data and materials \\ Datasets used in the current study are available from the corresponding author upon reasonable request.}

\section{Ethics approval and consent to participate}

Ethical clearance was obtained from the research ethics review committee of Ambo University, collage of Medicine and Health Sciences. A formal letter of cooperation was written to all selected Health institutions. Written informed consent was obtained from study participants after fully explaining the nature of the study in their local languages as it is attached in the questionnaire. The collected information was kept confidential without the name of the study participants.

\section{Consent for publication}

Not applicable.

\section{Competing interests}

Authors declared that they have no competing interest.

\section{Author details}

${ }^{1}$ Department of Midwifery, College of Medicine and Health Sciences, Ambo University, Ambo, Ethiopia. 'Department of Neonatal Nursing, Saint Paul's Hospital Millennium Medical College, Addis Ababa, Ethiopia. ${ }^{3}$ Department of Public Health, College of Medicine and Health Sciences, Ambo University, Ambo, Ethiopia.

Received: 4 October 2019 Accepted: 26 July 2020

Published online: 03 August 2020

\section{References}

1. Veronica Reis B, Deller C, Carr JS. Respectful Maternity Care Country experiences Survey Report November 2012 [Internet]. 2012. Available from: https://www.mhtf.org/document/respectful-maternity-care-countryexperiences/.

2. FederalMinistryofHealth(FMOH)Ethiopia. Respectful Maternity Care (RMC) and Partograph Training Resource Package [Internet]. Addis Ababa, Ethiopia; 2015. Available from: http://midwives.org.et/261

3. Windau-Melmer T. A Guide for Advocating for Respectful Maternity Care. [Internet]. Washington DC: Futures Group, Health Policy Project; 2013:11-96. Available from: https://www.whiteribbonalliance.org/wp-content/uploads/2 017/11/RMC-Guide_FINAL.pdf.

4. WhiteRibbonAlliance. Respectful maternity care: The Universal Rights of Child bearing women. 2011 Oct;1-6. Available from: www. whiteribbonalliance.org/respectfulcare.

5. Freedman LP, Ramsey K, Abuya T, Bellows B, Ndwiga C, Warren CE, et al. Defining disrespect and abuse of women in childbirth: a research, policy and rights agenda. Bull World Heal Organ. 2014;92(August):915-7.

6. Diana Bowser KH. Exploring evidence for disrespect and abuse in Facility based child birth Report of Landscape analysis [Internet]. Washington, DC: Translating Research into Action (TRAction) Project; 2010. Available from: http://www.tractionproject.org/content/exploring-evidence-disrespect-andabusefacility-based-childbirth-report-landscape-analysi-0.

7. WHO. The prevention and elimination of disrespect and abuse during facility-based childbirth WHO statement. World Health Organization [Internet]. 2014;(23). Available from: www.who.int.

8. Shiferaw S, Spigt M, Godefrooij M, Melkamu Y, Tekie M. Why do women prefer home births in Ethiopia? BMC Pregnancy Childbirth. 2013;13(5).

9. Bradley S, McCourt C, Rayment JPD. Disrespectful intrapartum care during facility-based delivery in sub-Saharan Africa A qualitative systematic review and thematic synthesis of women's perceptions and experiences. Soc Sci ence Med. 2016;169:157-70.

10. Sheferaw ED, Mengesha TZ, Wase SB. Development of a tool to measure women's perception of respectful maternity care in public health facilities. BMC Pregnancy Childbirth. 2016;16(1):67.

11. Bohren MA, Hunter EC, Munthe-Kaas HM, Souza J, Vogel JP, Gülmezoglu A. Facilitators and barriers to facility-based delivery in low- and middle-income countries: a qualitative evidence synthesis. Reprod Health. 2014;11(1):71-88.

12. Kruk ME, Kujawski S, Mbaruku G, Ramsey K, Moyo W, Freedman LP. Disrespectful and abusive treatment during facility delivery in Tanzania: a facility and community survey. Health Policy Plan. 2014;33 1-8.

13. Gebremichael MW, Worku A, Medhanyie AA, Edin K, Berhane Y. Women suffer more from disrespectful and abusive care than from the labour pain itself: A qualitative study from Women's perspective. BMC Pregnancy Childbirth. 2018;18(1):1-6.

14. Kujawski S, Mbaruku G, Freedman LP, Ramsey K, Moyo WKM. Association Between Disrespect and Abuse During Childbirth and Women's Confidence in Health Facilities in Tanzania. Matern Child Heal J. 2015;19(10).

15. Diana Bowser KH. Exploring Evidence for Disrespect and Abuse in FacilityBased Childbirth Report of a Landscape Analysis. USAID TRAction Project. Harvard School of Public Health. 2010;1-57.

16. Rosen HE, Lynam PF, Carr C, Reis V, Ricca J, Bazant ES. Direct observation of respectful maternity care in five countries: a cross-sectional study of health facilities in East and Southern Africa. BMC Pregnancy Childbirth. 2015;15:306.

17. Sando D, Ratcliffe H, Mcdonald K, Spiegelman D, Lyatuu G, Mwanyika-sando $M$, et al. The prevalence of disrespect and abuse during facility-based childbirth in urban Tanzania. BMC Pregnancy Childbirth [Internet]. 2016;16: 236. Available from: https://doi.org/10.1186/s12884-016-1019-4. 
18. Asefa A, Bekele D, Morgan A, Kermode M. Service providers' experiences of disrespectful and abusive behavior towards women during facility based childbirth in Addis Ababa, Ethiopia. Reprod Health. 2018;15(1):4.

19. Ethiopian Federal Ministry of Health. Health Sector Transformation Plan 2015/16-2019/20 [Internet]. Addis Ababa, Ethiopia; 2015. 5-29 p. Available from: https://ehia.gov.et/sites/default/files/Resources/HSTP Final Print 201511-27 Print size.pdf.

20. CentralStatisticalAgency[Ethiopia]. Ethiopia Mini Demographic and Health Survey 2014 [Internet]. Addis Ababa, Ethiopia; 2014. Available from: https:// phe-ethiopia.org/admin/uploads/attachment-1939-Ethiopia_Mini_ Demographic_and_Health_Survey_2014-2.pdf.

21. Kassa ZY, Husen S. Disrespectful and abusive behavior during childbirth and maternity care in Ethiopia: A systematic review and meta-analysis. BMC Res Notes [Internet]. 2019;12(1):2-7. Available from: https://doi.org/10.1186/ s13104-019-4118-2.

22. Asefa A, Bekele D. Status of respectful and non-abusive care during facilitybased childbirth in a hospital and health centers in Addis Ababa, Ethiopia. Reprod Health. 2015;12(33):1-9.

23. Wassihun B, Deribe L, Worede N, Gultie T. Prevalence of disrespect and abuse of women during child birth and associated factors in Bahir Dar town, Ethiopia. Epidemiol Health. 2018;40:e2018029.

24. Kilometers $L$. Ten, funded by the Bill \& Melinda Gates Foundation U and UP. Assessment of disrespect \& abuse during childbirth in two regions of Ethiopia: A qualitative study in four PHCUs (Kebet, Lante, Deneba and Denbecha). L10K Publication; 2014. p. 1-4.

25. Wassihun B, Zeleke $\mathrm{S}$. Compassionate and respectful maternity care during facility based child birth and women's intent to use maternity service in Bahir Dar, Ethiopia. BMC Pregnancy Childbirth. 2018;18(1):1-9.

26. Central Statistical Agency (CSA) [Ethiopia] and ICF. Ethiopia Demographic and Health Survey 2016: Key Indicators Report. Addis Ababa: CSA and ICF; 2016.

27. West Shewa Zone Health Offices. West Shewa zonal health Offices: Health Managment and information System 2017 Report. Ambo. 2017.

28. Sheferaw ED, Bazant E, Gibson H, Fenta HB, Ayalew F, Belay TB, et al. Respectful maternity care in Ethiopian public health facilities. Reprod Health. 2017;14(1):1-12.

29. MCHIP. Performance Standards for Respectful Maternity Care Standards: Care during labor and childbirth. 2011.

30. Gebremichael MW, Worku A, Medhanyie AA, Berhane Y. Mothers' experience of disrespect and abuse during maternity care in northern Ethiopia. Glob Health Action [Internet]. 2018;11(00). Available from: https:// doi.org/10.1080/16549716.2018.1465215.

31. Kitaw M, Tessema M. Respectful maternity care and associated factors among mothers in the immediate post - partum period, in public health facilities of Addis Ababa. Int J Pregnancy Child Birth. 2019;5(1):10-7.

32. Banks KP, Karim AM, Ratcliffe HL, Betemariam W, Langer A. Jeopardizing quality at the frontline of healthcare: Prevalence and risk factors for disrespect and abuse during facility-based childbirth in Ethiopia. Health Policy Plan. 2018;33(3):317-27.

33. Abuya T, Warren CE, Miller N, Njuki R, Ndwiga C, Maranga A, et al. Exploring the Prevalence of Disrespect and Abuse during Childbirth in Kenya. PLoS One. 2015;10(4):1-13.

34. Abuya T, Ndwiga C, Ritter J, Kanya L, Bellows B, Binkin N, et al. The effect of a multi-component intervention on disrespect and abuse during childbirth in Kenya. BMC Pregnancy Childbirth [Internet]. 2015;15:224. Available from: https://doi.org/10.1186/s12884-015-0645-6

35. Sethi R, Gupta S, Oseni L, Mtimuni A, Rashidi T, Kachale F. The prevalence of disrespect and abuse during facility-based maternity care in Malawi: Evidence from direct observations of labor and delivery. Reprod Health. 2017;14(1):1-10.

\section{Publisher's Note}

Springer Nature remains neutral with regard to jurisdictional claims in published maps and institutional affiliations.

Ready to submit your research? Choose BMC and benefit from:
- fast, convenient online submission
- thorough peer review by experienced researchers in your field
- rapid publication on acceptance
- support for research data, including large and complex data types
- gold Open Access which fosters wider collaboration and increased citations
- maximum visibility for your research: over 100M website views per year
At BMC, research is always in progress.
Learn more biomedcentral.com/submissions

